\title{
Determination of Residual Catechins, Polyphenolic Contents and Antioxidant Activities of Developed Theaflavin-3,3'-Digallate Rich Black Teas
}

\author{
Samuel Kimutai', John Wanyoko1, Thomas Kinyanjui' ${ }^{2}$, Stephen Karori3, \\ Augustine Muthiani ${ }^{3}$, Francis Wachira ${ }^{4}$ \\ ${ }^{1}$ KALRO-Tea Research Institute, Kericho, Kenya \\ ${ }^{2}$ Department of Chemistry, Egerton University, Nakuru, Kenya \\ ${ }^{3}$ Department of Biochemistry, Egerton University, Nakuru, Kenya \\ ${ }^{4}$ Association for Strengthening Agricultural Research in East and Central Africa, Entebbe, Uganda \\ Email:samuelkimutai@gmail.com
}

Received 2 December 2015; accepted 18 March 2016; published 21 March 2016

Copyright (C) 2016 by authors and Scientific Research Publishing Inc.

This work is licensed under the Creative Commons Attribution International License (CC BY).

http://creativecommons.org/licenses/by/4.0/

(c) (1) Open Access

\section{Abstract}

This study was carried out to characterize total residual catechins and their fractions, polyphenolic contents and antioxidant activities of black teas enriched with high levels of theaflavin-3,3'digallate. The made teas were processed from eleven selected cultivars. A comparative study was carried out between the processed teas and those from commercially grown Kenyan cultivars in relation to the above chemical parameters. A correlation matrix analysis was also conducted to find out whether a relationship existed between the antioxidant activities and the said chemical parameters. The total residual catechins were found to range between $3.10 \%$ and $8.08 \%$. The total polyphenol levels varied between $19.00 \%$ and $28.90 \%$, while the antioxidant activities of the teas ranged from $82.70 \%$ to $91.70 \%$. There was a significant $p<0.001$ correlation between the antioxidant activity and total polyphenols $(r=0.8948)$. There was also a high correlation $p<0.001$ between the antioxidant activity and total catechins $(r=0.8878)$. Out of the four catechin fractions, the antioxidant activity correlated most with EGCG $(r=0.8774)$. The total polyphenolic contents and antioxidant activities for most of the cultivars were comparable to those of the green tea reference standard. From the figures obtained, it can be concluded that the most of the newly developed black teas of the selected cultivars have higher quality and enhanced antioxidant activities and that they can be recommended for commercial production. 


\section{Keywords}

\section{Total Polyphenols, Antioxidant Activity, Residual Catechins, Theaflavins}

\section{Introduction}

Black tea is one of the most widely consumed beverages in the world owing to its refreshing taste and health benefits attributed to the antioxidants [1]. Black tea contains polyphenols, mainly the theaflavins (TFs), Thearubigens (TRs) and unoxidized catechins all of which contribute to the overall antioxidative property of the tea [2]. Black tea is processed through weathering of fresh tea leaves and then subjecting them to aeration process. The aeration process produces the brown coloured compounds (TFs and TRs) found in black tea [3].

Fresh tea leaves contain catechins, which comprise the reactants used in the formation of black tea TFs and TRs [4]. There are four major catechin fractions present in fresh leaves namely epicatechin (EC), epicatechin gallate (ECG), epigallocatechin (EGC) and epigallocatechin gallate all of which have unique biological properties. Epicatechin and epicatechin gallate have two hydroxyl groups on the B ring are commonly referred to as dihydroxycatechins while EGC and EGCG have three hydroxyl groups attached to the B ring hence referred to as tryhydroxycatechins [5] Figure 1.

Theaflavins are formed by enzymatic oxidative polymerization of dihydroxycatechins and trihydroxycatechins. The enzyme mediating the reaction is known as the polyphenol oxidase (PPO) [5]-[8]. There are four major TFs namely, simple theaflavins (TF), theaflavin-3-gallate (TF2A) theaflavin-3'-gallate (TF2B), and theaflavin-3,3'-digallate (TF3), Figure 2. Theaflavins give black tea its typical taste, brightness and contributes to the liquor color. The TRs are responsible for the infusion thickness [9].<smiles>Oc1cc(O)c2c(c1)O[C@H](c1ccc(O)c(O)c1)[C@H](O)C2</smiles>

Epicatechin<smiles>Oc1cc(O)c2c(c1)O[C@H](c1cc(O)c(O)c(O)c1)[C@H](O)C2</smiles>

Epigallocatechin<smiles>O=C(O[C@H]1Cc2c(O)cc(O)cc2O[C@@H]1c1ccc(O)c(O)c1)c1cc(O)c(O)c(O)c1</smiles>

Epicatechin gallate<smiles>O=C(O[C@H]1Cc2c(O)cc(O)cc2O[C@@H]1c1cc(O)c(O)c(O)c1)c1cc(O)c(O)c(O)c1</smiles>

Epigallocatechin gallate

Figure 1. The four major catechin fractions. 
<smiles>[R20][C@H]1Cc2c(O)cc(O)cc2O[C@H]1[C@H]1Cc2c([C@H]3Oc4cc(O)cc(O)c4C[C@H]3O)cc(O)c(O)c2C(=O)C(O)C1</smiles>

Theaflavins (Theaflavin: R1=R2=H; Theaflavin-3'-gallate R1= galloyl, R2=H; Theaflavin-3-gallate R1=H, R2=galloyl,Theaflavin-3,3'-gallate: R1=R2=galloyl)

\section{Figure 2. The four major theaflavins fractions.}

The health benefits derived from tea consumption are believed to arise from the antioxidant property of the polyphenolic substances in tea, and in particular their effectiveness in scavenging reactive oxygen species. A number of studies have reported the antioxidant capacity of black tea polyphenols and green tea polyphenols having comparable effectiveness in relation to scavenging free radicals [10].

Kenya is the world's leading exporter of black tea exporting over 400,000 tons every year. However, there has been an increase in world tea production than the world demand. This is despite the increase in the cost of production [9]. Only producers of high quality black tea will sell them at higher prices. One of the Kenya's strategic approaches is to diversify and add value to the tea products for the domestic and export markets and therefore the Tea Research Institute recently developed black teas with optimized health benefits for the purpose of increasing its intrinsic value [11].

The International Standards Organization (ISO) just introduced the concept of characterizing teas in the tea export business based on levels of polyphenols. Similarly, consumers are increasingly becoming aware of the health benefits of black tea hence the beverage's price will be determined by their level of bioactivity. There are already efforts to encourage black tea exporting firms to use biosensing technology to facilitate the rapid screening of tea samples for their antioxidative capacity [12].

Numerous studies have reported a positive correlation between antioxidant activities and TF3, total poyphenols and residual catechins. However, most of tea research work done has been on characterization of various bioactive active compounds and very little on how to enhance the antioxidant activity. Authors [11] had carried out a study on eleven Kenyan tea cultivars that led to the development of black teas enriched with high TF3 levels, Table 1. This research work sought to characterize the various bioactive compounds in those manufactured black teas.

\section{Materials and Method}

\subsection{Tea Samples}

The black teas were sourced from the TRI's miniature factory. The teas had been manufactured using a method prescribed by [11] and their TF3 profiles are already known.

\subsection{Determination of Residual Catechins}

A modified HPLC method of [13] was used for analysis of the black tea catechins. A Shimadzu LC 20 AT HPLC system fitted with a SIL 20A auto sampler and a SPD-20 UV visible detector with a class LC 10 
Table 1. Optimized TF3 levels of the manufactured black teas of the selected cultivars.

\begin{tabular}{ccc}
\hline Cultivars & TF3 (\%) \\
TRFK 832/8 & $0.59^{\mathrm{a}}$ \\
TRFK 824/1 & $0.56^{\mathrm{b}}$ \\
SC 12/28 & $0.50^{\mathrm{c}}$ \\
TRFK 301/3 & $0.49^{\mathrm{c}}$ \\
Ejulu & $0.45^{\mathrm{d}}$ \\
SC 31/37 & $0.43^{\mathrm{de}}$ \\
TRFK 655/1 & $0.43^{\mathrm{de}}$ \\
TRFK 831/11 & $0.41^{\mathrm{e}}$ \\
K-Purple & $0.32^{\mathrm{f}}$ \\
TRFK 301/6 & $0.30^{\mathrm{f}}$ \\
TRFK 6/8 & $0.26^{\mathrm{g}}$ \\
CV & 3.48 \\
\hline
\end{tabular}

Means followed by the same letter are not significantly different at $\mathrm{p}<0.05$. Source: [11].

chromatography workstation was used for analysis of the prepared samples. A Gemini 5 Um C6-phenyl, 250 $\mathrm{mm} \times 4.6 \mathrm{~mm}$ (Phenomenex, Torrance, CA, USA) separation column with a Reodyne precolumn filter disk was used. A gradient elution was carried out using the following solvent system: Mobile phase A (acetonitrile/acetic acid/double distilled water-9:2:89 v/v/v), mobile phase B (acetonitrile/acetic acid/ double distilled water-80/2/18 $\mathrm{v} / \mathrm{v} / \mathrm{v}$ ). The mobile phase composition for a binary gradient condition started at $100 \%$ solvent A for 10 minutes then over 15 minutes a linear gradient to $60 \%$ mobile phase A, 32\% mobile phase B and held at this composition for 7 minutes. The condition was reset to $100 \%$ mobile phase A and then allowed to equilibrate for 10 minutes before the next injection. The flow rate of mobile phase was $1 \mathrm{ml} / \mathrm{min}$ and the temperature in the column was maintained at $35^{\circ} \mathrm{C} \pm 0.5^{\circ} \mathrm{C}$. The identification of individual catechins was carried out by comparing the retention times and UV-absorbance of unknown peaks with peaks obtained from the mixed known catechin standards under the same conditions. The quantification of catechins was performed at $278 \mathrm{~nm}$ and was achieved using a caffeine standard with a calibration curve $\mathrm{R}=0.9984$ in conjunction with the consensus individual catechin relative response factor (RRF) values with respect to caffeine calculated on a dry matter basis. Total catechin as percentage by mass on a sample dry matter basis was got by summing individual catechins as shown below.

$$
\% \text { Total catechins }=[\% \text { ECG }+\% \text { EC }+\% \text { ECCG }+\% \text { C }] \text { content . }
$$

\subsection{Determination of Total Polyphenols}

The black teas of the selected cultivars were milled before analysis. For the analysis, $0.2 \mathrm{~g}$ of the sample was weighed into an extraction tube. Five millilitres of hot $70 \% \mathrm{v} / \mathrm{v}$ methanol/distilled water was poured into the sample as an extraction mixture and vortexed. Warming of the extraction tube was continued in the water bath maintained at $70^{\circ} \mathrm{C}$ for 10 minutes with vortexing after every 5 minutes (the sample was vortexed at zero minute, after 5 minutes and after the 10 minutes). After that, the samples were then centrifuged at 3500 revolution per minute (rpm) for 10 minutes. The supernatant was decanted into a $100 \mathrm{ml}$ graduated test tube and the extraction procedure repeated. The extracts were combined and made up to $10 \mathrm{ml}$ with warm $70 \%$ methanol/water mixture. The Folin-Ciocalteu phenol reagent method was used to determine total polyphenols as described by [9]. The reagent was chosen because it has phosphotungistic acid as oxidants. One millilitre of the sample extract was transferred to a $100 \mathrm{ml}$ volumetric flask and topped to the mark with distilled water and mixed. One millilitre of the diluted sample extract was transferred in duplicate into separate tubes. Five millilitres of ten percent (10\% v/v) of dilute Folin-Ciocalteu reagent was pipetted into each tube and mixed. Within 3 - 8 minutes after addition of the Folin-Ciocalteu phenol reagent, $4 \mathrm{ml}$ of $7.5 \% \mathrm{w} / \mathrm{v}$ sodium carbonate solution was added to each tube then a stopper was fitted and mixed well. The mixture was allowed to stand at room temperature for 60 minutes and 
then optical densities (OD) measured using a CE 393 Cecil digital grating spectrophotometer set at $765 \mathrm{~nm}$. A calibration curve was obtained for gallic acid over a concentration range of $10 \mu \mathrm{g} / \mathrm{ml}$ to $50 \mu \mathrm{g} / \mathrm{ml}$. The OD readings of the test samples were referenced to the calibration curve to determine the total polyphenols content of the tea samples.

\subsection{Antioxidant Activities of the Black Teas}

Five grams of the ground black tea leaves was weighed into a round bottomed flask and $100 \mathrm{ml}$ of boiling distilled water added and infused for 5 minutes. The infusion was then filtered through a nylon mesh and a filter paper and then refiltered again through Whatman 54 filter paper $(0.45 \mu \mathrm{m})$.

\subsubsection{Measurement of Total Soluble Solids}

Ten milliliters of the infusion was pipette into pre-weighed moisture dishes and dried in the oven at $10^{\circ} \mathrm{C}$ for 12 hours. The remaining extracts where frozen at $-18^{\circ} \mathrm{C}$. The weight of the soluble solids was determined by weighing the dried moisture dishes and expressed as $\mathrm{mg} / \mathrm{ml}$.

\subsubsection{Preparation of DPPH Solution}

Eight hundred milliliters of absolute ethanol and $20 \mathrm{ml}$ of distilled water were mixed together. After that, 0.024 g of DPPH was weighed and added to the methanolic solution and then stirred to dissolve.

\subsubsection{Determination of the Antioxidant Activity}

The soluble solids of the extracts were standardized to give a solution of $0.5 \mathrm{mg} / \mathrm{ml}$. A methanolic solution of 50 $\mu \mathrm{l}$ of tea solution was taken and mixed with $2 \mathrm{ml}$ of DPPH solution. A blank solution was made by adding $50 \mu \mathrm{l}$ of distilled and mixed with $2 \mathrm{ml}$ DPPH solution and left to stabilize for $15 \mathrm{~min}$. The absorbance of the blank ( $\left.\mathrm{A}_{\mathrm{b}}\right)$ was read at $515 \mathrm{~nm}$ and then followed by those of the samples $\left(\mathrm{A}_{\mathrm{a}}\right)$. The antioxidant activity was calculated as follows.

$$
\% \text { inhibition against DPPH }=\left[\left(A_{b}-A_{a}\right) / A_{b}\right] \times 100
$$

where

$$
\begin{aligned}
& A_{b}=\text { absorbance of the blank sample. } \\
& A_{a}=\text { absorbance of the test sample after } 15 \text { minutes. }
\end{aligned}
$$

\subsection{Data Analyses}

The data analyses were conducted using the GENSTAT Discovery Edition 4 software. The results were presented as graphs and the mean separation was carried out using Duncan Multiple's Range Test (DMRT) where the probability limits was set as $\mathrm{p} \leq 0.05$.

\section{Results and Discussion}

\subsection{Residual Catechins}

The results on the unoxidized catechin levels are shown in Figures 3-7. There were significant p $<0.05$ differences in the levels of the catechin fraction for all cultivars. Cultivar Ejulu, Figure 3, had the highest levels of residual EGC, (1.37\%) while 301/3 had the least levels $(0.20 \%)$ and not significantly p $<0.05$ different from TFK 832/8, (0.21\%).

Cultivar TRFK 831/11 had the highest EGCG levels (2.20\%), as shown in Figure 4, while TRFK 301/6 had the least levels of residual EGCG (0.84\%). Cultivars SC 12/28 and TRFK 832/8 were not significantly different in the residual EGCG levels.

Cultivar TRFK 301/6 had the highest EC levels (1.41\%) while SC 31/37 had the least levels (0.36\%), as shown in Figure 5. Cultivar TRFK 824/1 and TRFK 832/8 were not significantly different in their levels of EC. Likewise, TRFK 301/3 and SC 12/28 were not significantly different in their EC levels. Cultivar TRFK 6/8 and TRFK 655/1 were also not significantly different with respect to their EC contents.

Ejulu had the highest ECG levels, (3.55\%) even though the levels were not significantly p $<0.05$ different with those of TRFK 831/11 (3.47\%) as shown in Figure 6. The cultivar SC 31/37 had the least ECG levels (0.70\%). There was no significant difference in ECG levels between TRFK 301/3 and TRFK 301/6. There was 


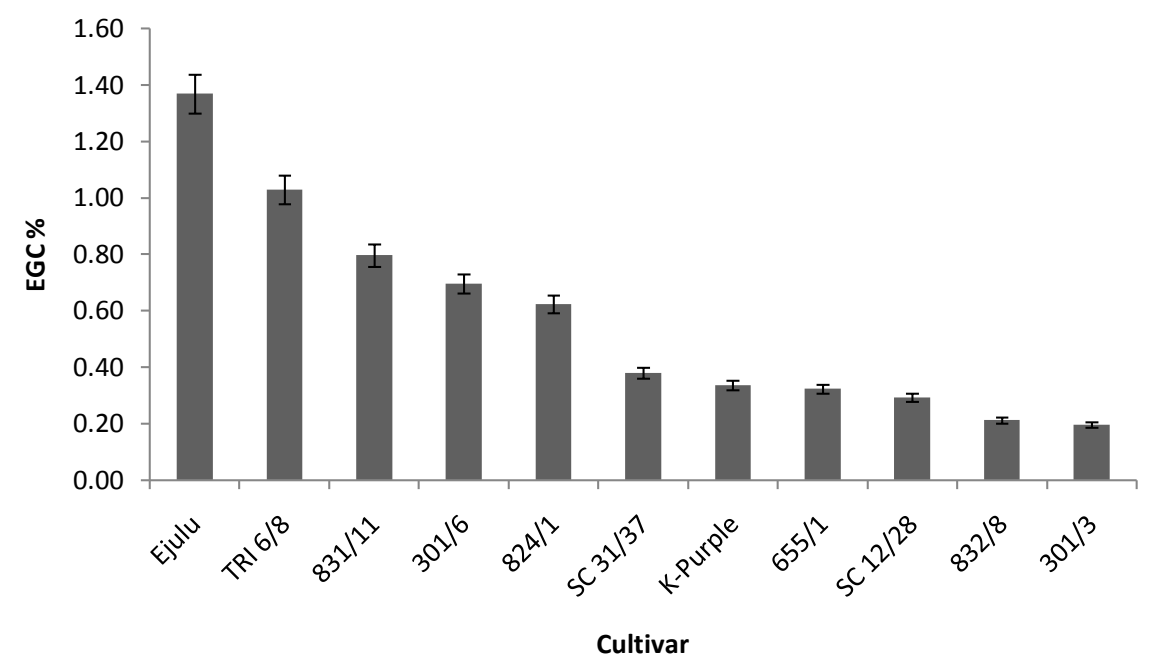

Figure 3. Residual EGC of the manufactured teas.

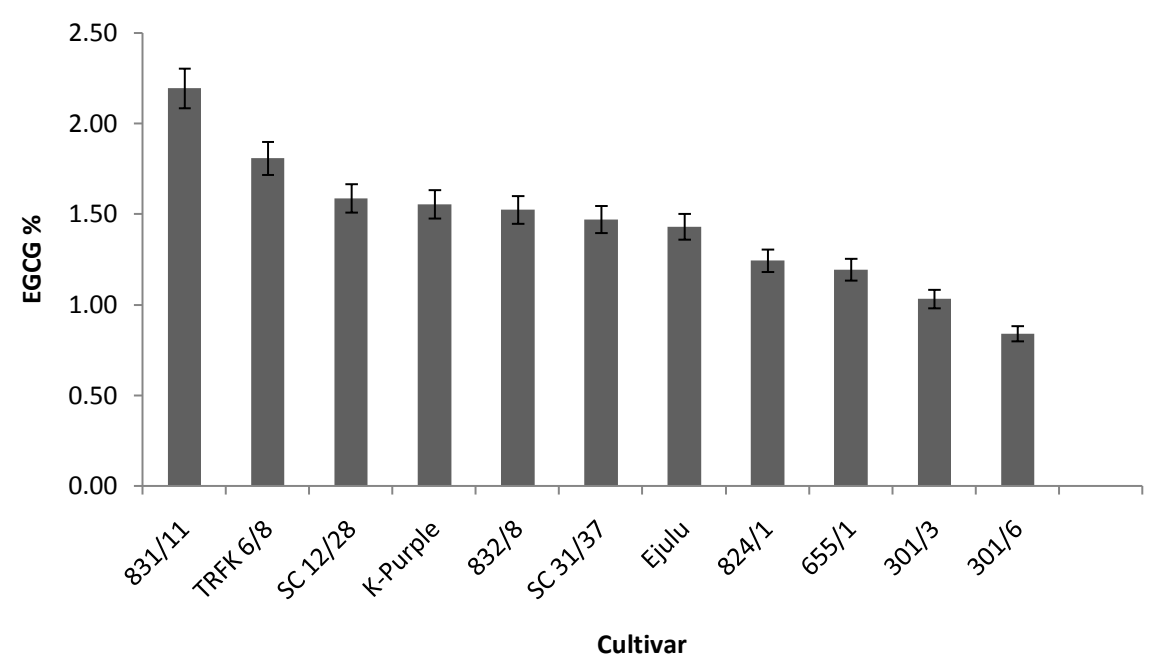

Figure 4. Residual EGCG of the manufactured teas.

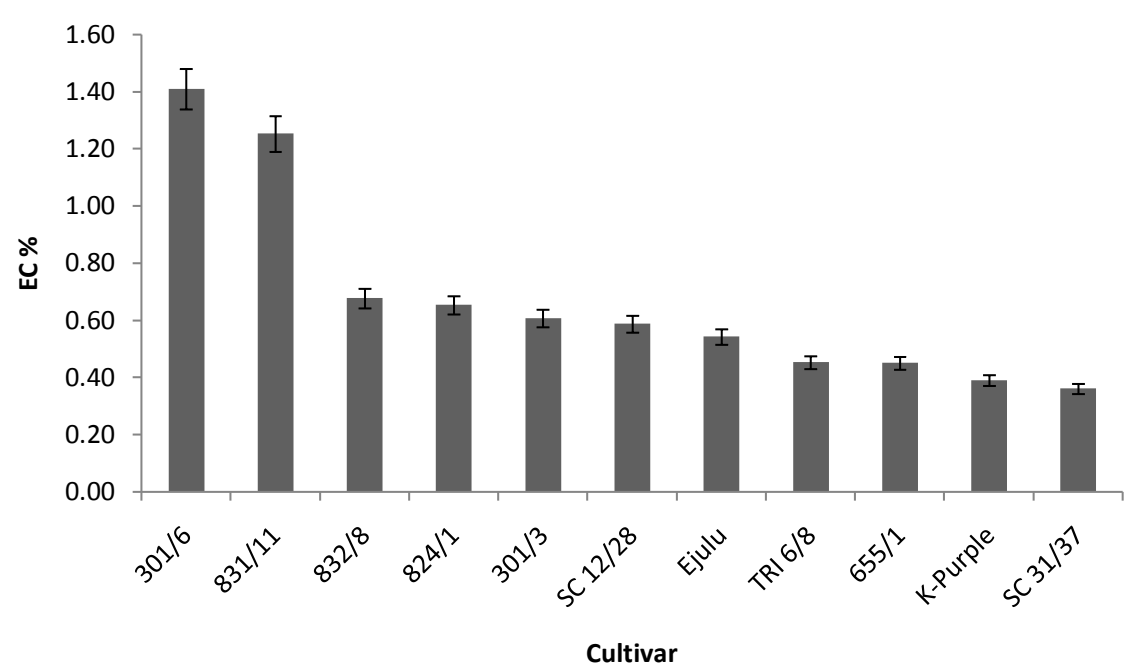

Figure 5. Residual EC of the manufactured teas. 

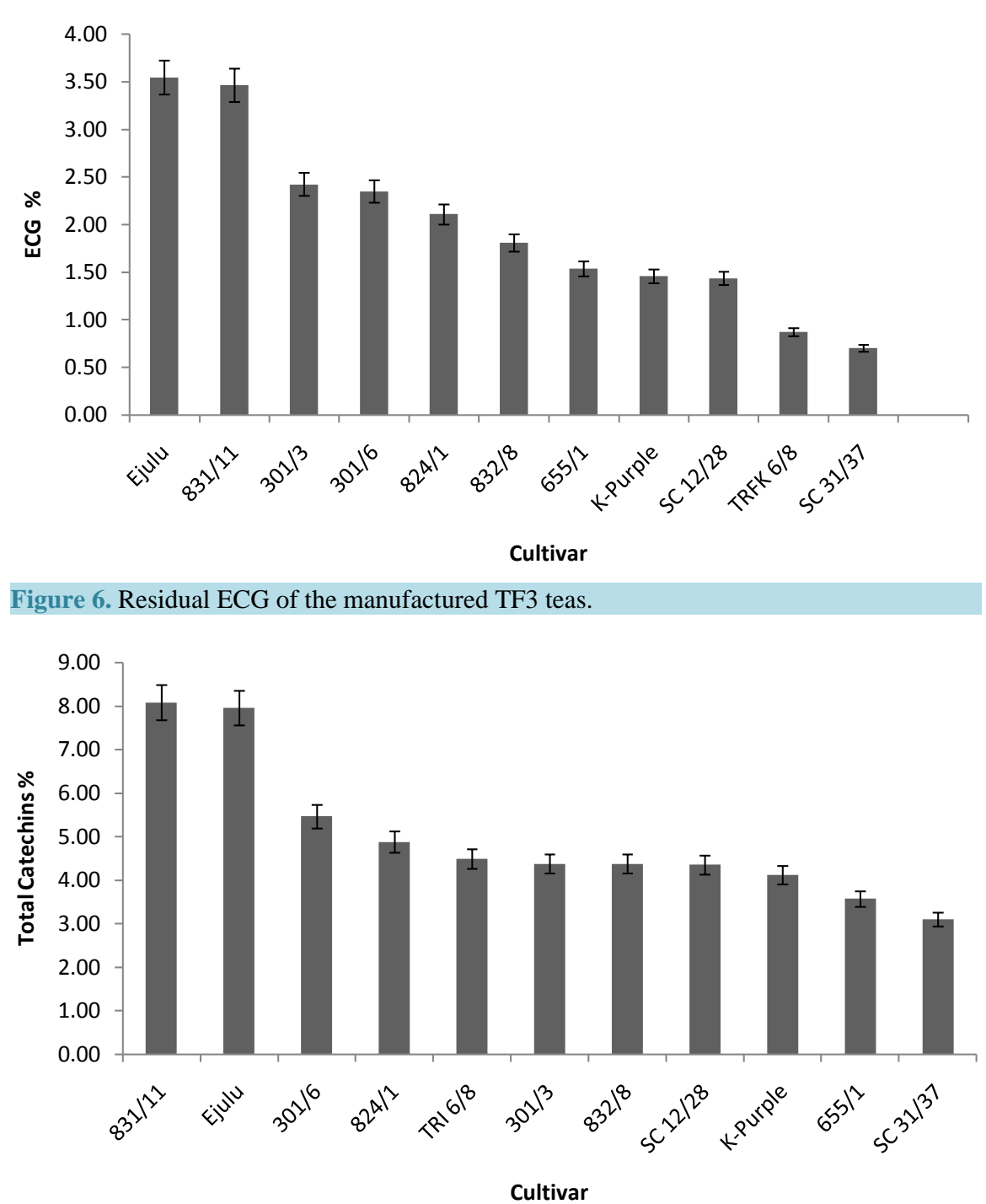

Figure 7. Total residual catechins of the manufactured teas.

also no significant difference between K-Purple and SC 12/28 in their levels of ECG.

There was significant $\mathrm{p}>0.05$ difference in the levels of total catechins (total catechins) between the black teas of the processed clones as shown in Figure 7. Cultivar TRFK 831/11 had the highest levels of total catechins and not significantly different from that of Ejulu as seen in Figure 7. Cultivar SC 31/37 had the least amounts of total catechins. Cultivars TRFK 301/3, TRFK 832/8 and SC 12/28 were not significantly different in their total catechins levels.

EGC and EGCG comprise the trihydroxy flavan-3-ols while EC and ECG constitute the dihydroxyflavan-3-ol. It has been thought that EGCG and ECG make up about 70\% of the total catechins [14]. During the selection process of tea cultivars with potential to produce TF3 rich tea, Ejulu ranked the first having the highest combination of ECG and EGCG and EGC [11]. The cultivar's high levels of residual EGC and ECG shows that most of these compounds were not oxidized during the black tea processing. The high levels of EC and EGCG in TRFK 831/11 means that most of these molecules did not react. The low levels of EC and ECG in SC 31/37 confirms the fact that most of the two catechin fraction ended up being depleted in the formation of the simple TFs. The variation in the rate of catechin depletion among the clones is consistent with the findings by [15] who attributed the variation to the difference in reduction potential of the catechin fractions. For instance in green tea, the dominant catechins are the trihydroxylated catechins however in black tea the dihydrolylated flavan-3-ols comprise the bulk of the main residual catechin. This is because the trihydroxylated catechins, (EGC and EGCG), 
oxidize at much faster than the dihydroxylated catechins (EC and ECG) [16]-[19]. Findings from studies done by [20] reported that that EC and ECG were the limiting reactants in the formation of simple theaflavins. The low levels of ECG in cultivar TRFK 6/8 attests to the fact since most of it had been consumed in the formation of TFs. The HPLC analysis of the flavan-3-ols in the black teas showed that the catechin fractions are eluted in different patterns. The nongallated flavan-3-ols, EGC and catechin EC were eluted prior to the gallated catechins, ECG and EGCG. This is because the nongallated flavan-3-ols are polar and therefore bound less tightly by the non-polar stationary phase (C18 column) upon the introduction of the polar mobile phase ( $9 \%$ acetonitrile). The gallated flavan-3-ols, were eluted last since they were tightly bound to the column [21].

\subsection{Total Polyphenols}

The results for the total polyphenols of the TF3 rich black teas are shown in the Figure 8. The levels ranged from $28.96 \%$ to $19.08 \%$. Ejulu had the highest levels of polyphenolic content while K-purple had the least. However there was no significant $\mathrm{p}<0.05$ difference between Ejulu and TRFK 831/11 and the green tea reference sample in their total polyphenols content. Cultivars TRFK 832/8, TRFK 824/1, SC 12/28 and TRFK 301/3 did not vary significantly with respect to the total polyphenols levels. There was also no significant variation between the black tea reference standard (Ref Blck) and TRFK 6/8 and TRFK 6551/1 in the total polyphenol concentrations.

Green tea processed from TRFK 6/8 has often been used for reference purposes (Ref Grn) when carrying out polyphenolic content studies since it has been found to have the highest levels of total polyphenols compared with tea form other parts of the world [22]. From the results of this study however, the green tea reference standard ranked the third implying that other superior cultivars with enhanced levels of antioxidants have been developed over time. The high levels of total polyphenols in Ejulu and TRFK 831/11 could be due to their high levels of total residual catechins. Cultivars that had high total polyphenols contents were also found to have high residual total catechins levels, consistent with what [19] [23] [24] found, implying that the catechins constitute the bulk components of the polyphenols.

The differences in the total polyphenols levels between black teas of the selected cultivars give a basis to the tea breeders when doing improvement and management of tea quality. Studies conducted on total polyphenols levels between of black teas from Kenya and Japan and China reported that the Kenyan black teas had higher total polyphenols levels. It was also found out that the Kenyan black tea had higher total polyphenols levels than green tea from the both countries [25]. In addition, it has been reported that the polyphenolic content of green teas from Argentina and Malaysia ranged between 19\% and 11\% while those of the black teas varied from $8 \%$ to $6 \%$ [26]. Other authors have found the average polyphenolic content of commercially available black teas in Australia to be $16 \%$ [27]. The high polyphenol levels in Kenyan black tea is expected since the tea breeding

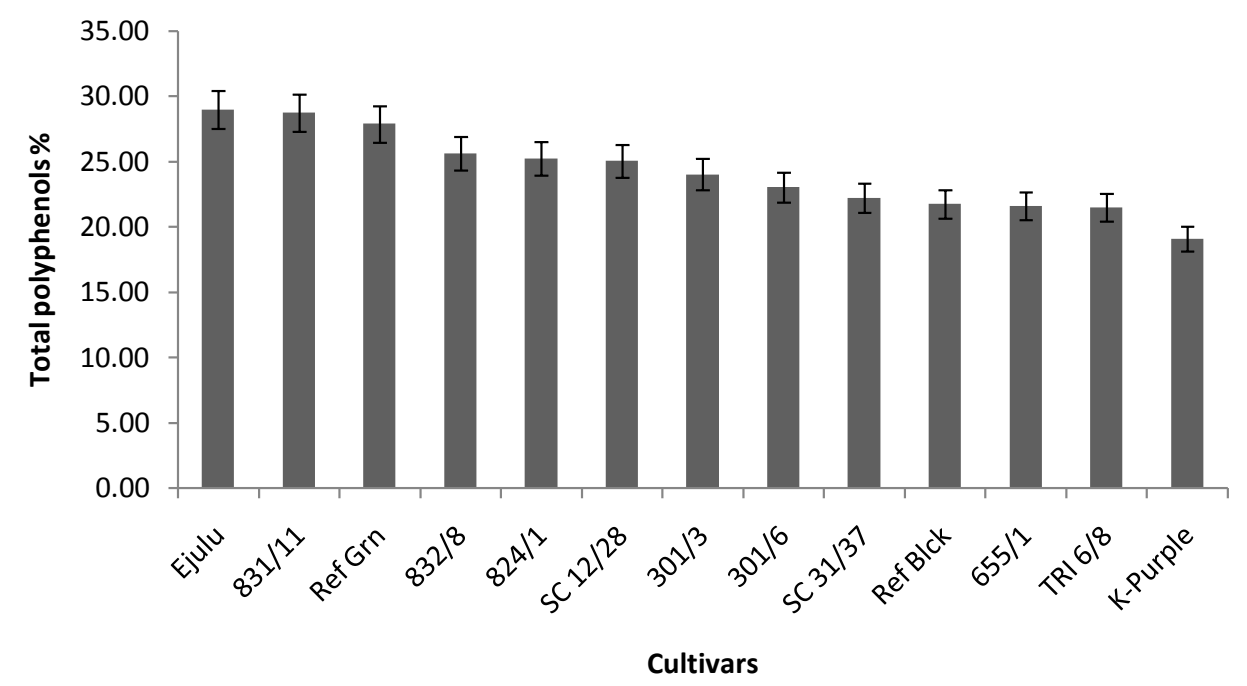

Figure 8. Total polyphenolic content of the manufactured teas. 
programmes in Kenya has consistently conducted research on coming up with cultivars endowed with high levels of total polyphenols so as to produce black teas with enhanced levels of TF and TR contents. The high plolyphenolic contents of Kenyan tea cultivars could also be attributed to the botanical origin, agronomical practices, and leaf morphology.

\subsection{Antioxidant Activities}

The results for the antioxidant capacities of the manufactured black teas are presented in Figure 9. As shown from the figure, antioxidant activities for the black teas were found to vary from (91.79\%) to (82.71\%). Cultivar TRFK 831/11 had the highest antioxidant activity even though the values did not differ significantly with those of green tea reference standard Ref Grnm, TRFK 824/1, Ejulu, and SC 31/3. Cultivar TRFK 301/6 had the least antioxidant activity, differing significantly $\mathrm{p}<0.05$ with all the other cultivars.

The high antioxidant activity reported could be attributed to high total polyphenols content. It could also be attributed to the high levels of TF3 as reported by [11] since most of the cultivars that exhibited high antioxidant activity also had relatively high levels of TF3 contents. This shows that cultivars whose black teas have high concentration of TF3 are also likely to have high antioxidant activity. The low antioxidant activity exhibited by cultivar TRFK 301/6 could be as a result of the low residual EGCG content. The comparability of the green tea reference standard with most of the cultivars with regards to their antioxidant activity shows that there may be no significant difference in antioxidant activity between green teas and the TF3 enriched black teas. Studies by other authors [28], [10] reported that black teas had comparable antioxidant activity to green teas.

Researchers [6] tried to propose the antioxidative mechanism by studying the oxidation products of TFs. In their studies, the authors reported that theanaphthoquinone was the main radical reaction product and that the benzotropolone moiety of TFs played an important role in ensuring an antioxidant protection for the preferred oxidation site. Theaflavins have been thought to have a higher reduction potential than the green tea's EGCG and more effective in scavenging superoxide radicals. This has been attributed to the ease of benzotropolone's electron donation and the subsequent stabilization of the resonance structures formed [29]. The antioxidative mechanism of TFs however warrants further investigation as there have been a number of proposed mechanisms by various tea researchers some of whose findings conflict one another.

\subsection{Correlation Analysis between Antioxidant Activity and Other Chemical Parameters}

Table 2 presents data on the correlation between the antioxidant activity and other chemical parameters present

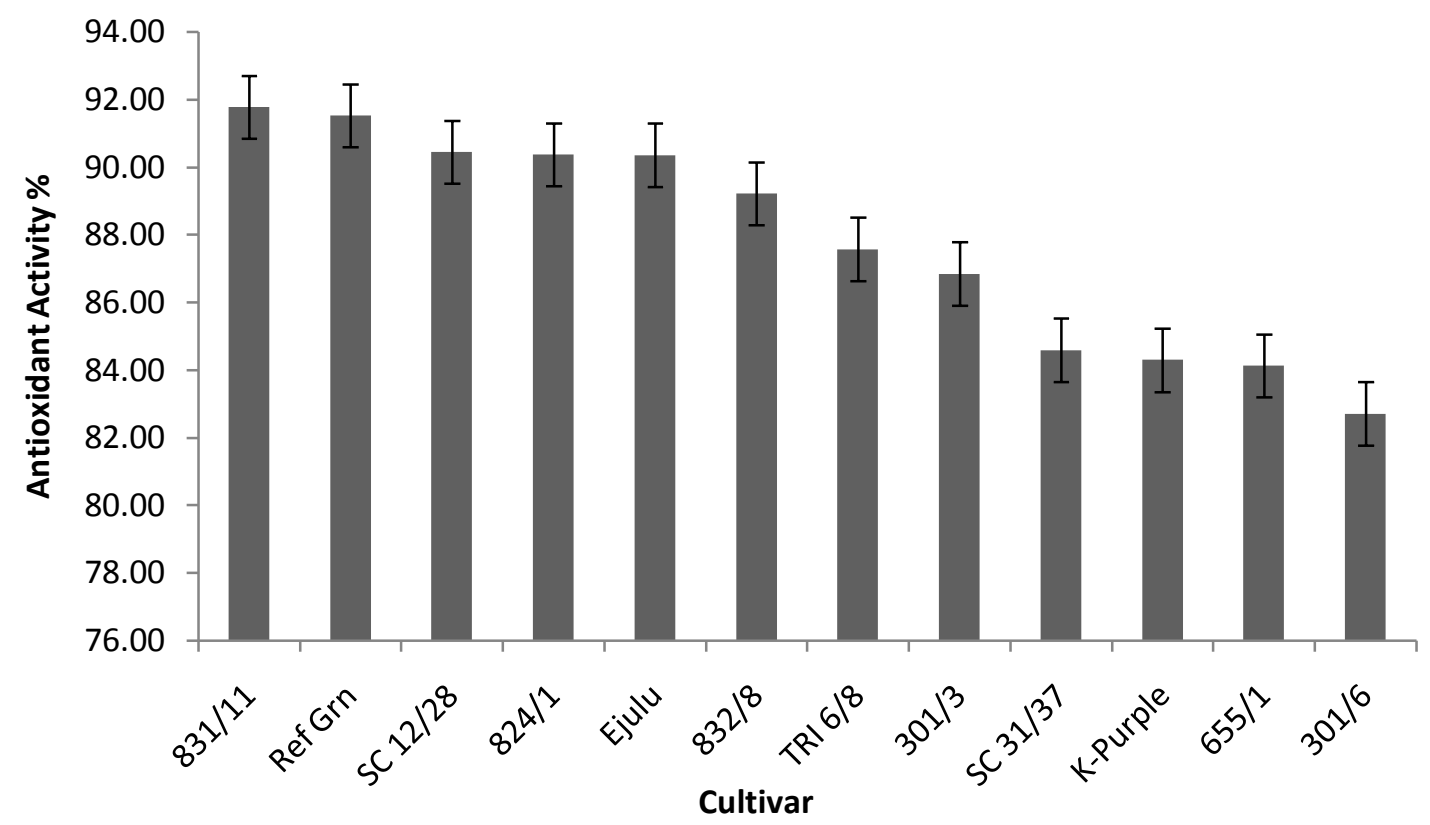

Figure 9. Antioxidant activities (\%) of the manufactured teas. 
Table 2. Correlation coefficient analyses between antioxidant activity and other chemical parameters.

\begin{tabular}{|c|c|c|c|c|c|c|c|c|c|}
\hline EC & & & & & & & & & \\
\hline ECG & $0.573^{*}$ & & & & & & & & \\
\hline EGC & $0.1906^{\mathrm{NS}}$ & $0.4717^{\mathrm{NS}}$ & & & & & & & \\
\hline EGCG & $-0.0408^{\mathrm{NS}}$ & $0.0539^{\mathrm{NS}}$ & $0.2557^{\mathrm{NS}}$ & & & & & & \\
\hline $\mathrm{TC}$ & $0.5583^{*}$ & $0.902^{* *}$ & $0.7262^{*}$ & $0.3583^{\mathrm{NS}}$ & & & & & \\
\hline TF3 & $-0.1512^{\mathrm{NS}}$ & $0.1752^{\mathrm{NS}}$ & $-0.3751^{\mathrm{NS}}$ & $-0.1055^{\mathrm{NS}}$ & $-0.0507^{\mathrm{NS}}$ & & & & \\
\hline TP & $0.412^{\mathrm{NS}}$ & $0.7937^{* *}$ & $0.4383^{\mathrm{NS}}$ & $0.2821^{\mathrm{NS}}$ & $0.7968^{* *}$ & $0.5032^{\mathrm{NS}}$ & & & \\
\hline AA & $0.0804^{\mathrm{NS}}$ & $0.4773^{\mathrm{NS}}$ & $0.3178^{\mathrm{NS}}$ & $0.8774^{* *}$ & $0.8878^{* *}$ & $0.8854^{* *}$ & $0.8948^{* *}$ & & \\
\hline \multirow[t]{2}{*}{ EGC } & $0.1906^{\mathrm{NS}}$ & $0.4717^{\mathrm{NS}}$ & $1^{\mathrm{NS}}$ & $0.2557^{\mathrm{NS}}$ & $0.7262^{*}$ & $-0.3751^{\mathrm{NS}}$ & $0.4383^{\mathrm{NS}}$ & $0.3178^{\mathrm{NS}}$ & \\
\hline & EC & ECG & EGC & EGCG & TC & TF3 & TP & AA & EGC \\
\hline
\end{tabular}

AA = Antioxidant activity, TC = Total catechins, $\mathrm{TP}=$ Total polyphenols, Superscript NS = Not Significant.

in the TF3 rich black teas. Total polyphenols correlated significantly $\mathrm{p}<0.001$ with anti oxidant activity ( $\mathrm{r}=$ 0.8948). There was also a significant $\mathrm{p}<0.001$ correlation between total catechins and anti oxidant activity $(\mathrm{r}=$ 0.8878), EGCG and anti oxidant activity, $\mathrm{p}<0.001(\mathrm{r}=0.8774)$, Total TFs and anti oxidant activity, $\mathrm{p}<0.001$ $(\mathrm{r}=0.7199)$ and TF3 and anti oxidant activity $\mathrm{p}<0.001(\mathrm{r}=0.8854)$. Even though black teas with high total polyphenols content exhibited high antioxidant activity, they have often been found to be bitter in their taste because of the excess residual catechins present. The TF3 is attributed to giving desirable astringency and mouth feel to black tea [30]. The significant correlation between anti oxidant activity and TF3 offers a promising prospect in the development of black teas with enhanced antioxidative properties. It is important to note that TF3 had a higher correlation coefficient with anti oxidant activity than EGCG, which is known, to be the most potent of the catechin fractions in green tea. This means that the conversion of fresh green tea leaves to black tea does not significantly affect the radical scavenging activity of the black tea, an observation that is in agreement with what [10], [31] found out.

When thinking about the health benefits of the black tea as antioxidants [16] anticancer [32] [33] and anti-inflammatory [1] agents, it should be considered that the direct absorption of the biomolecules by the digestive tract is expected to be lower for black tea than for green tea catechins [34], since the black tea polyphenols have larger molecular masses than those of single unit green tea catechins. It has been reported that the inhibition of digestive enzymes may of be significant importance, because polyphenols with larger molecular weights have the tendencies to interact with proteins by forming hydrophobic and hydrogen bonds [35] which usually results in inhibition enzymes like amylase and lipase which hydrolyze starch and truglyceride respectively. The inhibition of these enzymes has been associated with decreased incidence of common diseases caused by carbohydrates and fat rich diets. More research on the enzyme inhibition process would be necessary so as to give more information about digestive tract enzyme interactions with TFs.

\section{Conclusion}

Most of the cultivars' polyphenolic contents and antioxidant activities were comparable to those of the reference standard. Black teas with high total polyphenolic content also exhibited higher levels of total residual catechins. There was a high correlation between antioxidant activities and TF3, total polyphenols and total residual catechins. This means that black teas with optimized TF3 levels are most likely to have increased antioxidant capacities.

\section{Acknowledgements}

The authors of this paper would like to thank the Tea Research Institute for allowing and facilitating the publication of this work. The authors would also like to thank the National Council of Science and Technology Innovation for funding the project.

\section{References}

[1] Aneja, R., Odoms, K., Denenberg, A.G. and Wong, H.R. (2004) Theaflavin, a Black Tea Extract, Is a Novel Anti-In- 
flammatory Compound. Critical Care Medicine, 32, 2097-2103.

http://dx.doi.org/10.1097/01.CCM.0000142661.73633.15

[2] Yang, C.S., Chung, J.Y., Yang, G.Y., Li, C., Meng, X. and Lee, M.J. (2000) Mechanisms of Inhibition of Carcinogenesis by Tea. BioFactors, 13, 73-79. http://dx.doi.org/10.1002/biof.5520130113

[3] Balentine, D.A. (1992) Manufacturing and Chemistry of Tea. ACS Symposium Series, 506, 102-117. http://dx.doi.org/10.1021/bk-1992-0506.ch008

[4] Li, S., Lo, C.-Y., Pan, M.-H., Lai, C.-S. and Ho, C.-T. (2013) Black Tea: Chemical Analysis and Stability. Food \& Function, 4, 10-18. http://dx.doi.org/10.1039/C2FO30093A

[5] Lou Heiss, M. (2007) The Book of Tea. Gastronomica, 7, 113-114. http://dx.doi.org/10.1525/gfc.2007.7.4.113

[6] Tanaka, T., Inoue, K., Betsumiya, Y., Mine, C. and Kouno, I. (2001) Two Types of Oxidative Dimerization of the Black Tea Polyphenol Theaflavin. Journal of Agricultural and Food Chemistry, 49, 5785-5789. http://dx.doi.org/10.1021/jf010842x

[7] Liu, S., Lu, H., Zhao, Q., He, Y., Niu, J., Debnath, A.K., Wu, S. and Jiang, S. (2005) Theaflavin Derivatives in Black Tea and Catechin Derivatives in Green Tea Inhibit HIV-1 Entry by Targeting gp41. Biochimica et Biophysica Acta (BBA)—General Subjects, 1723, 270-281. http://dx.doi.org/10.1016/j.bbagen.2005.02.012

[8] Song, Y.-A., Park, Y.-L., Yoon, S.-H., Kim, K.-Y., Cho, S.-B., Lee, W.-S., Chung, I.-J. and Joo, Y.-E. (2011) Black Tea Polyphenol Theaflavin Suppresses LPS-Induced ICAM-1 and VCAM-1 Expression via Blockage of NF- $\kappa$ B and JNK Activation in Intestinal Epithelial Cells. Inflammation Research, 60, 493-500. http://dx.doi.org/10.1007/s00011-010-0296-z

[9] Kilel, E.C., Wanyoko, J.K., Faraj, A.K. and Wachira, F.N. (2013) Plain Black Tea Quality Parameters of Purple Leaf Coloured Tea Clones in Kenya. International Journal of Research in Chemistry and Environment, 3, 81-88.

[10] Karori, S.M., Wachira, F.N., Wanyoko, J.K. and Ngure, R.M. (2007) Antioxidant Capacity of Different Types of Tea Products. African Journal of Biotechnology, 6, 2287-2296.

[11] Kimutai, S., Kinyanjui, T., Wanyoko, J.K., Wachira, F.N., Karori, S.M and Muthiani, A. (2015) Optimization of Aeration Times in the Development of Theaflavin-3,3'- Digallate Rich Black Teas. American Journal of Plant Sciences, 6, 3001-3012.

[12] Haase, G. (2010) Functional and Speciality Beverage Technology, 20.

[13] Khokhar, S., Venema, D., Hollman, P.C.H., Dekker, M. and Jongen, W. (1997) A RP-HPLC Method for the Determination of Tea Catechins. Cancer Letters, 114, 171-172. http://dx.doi.org/10.1016/S0304-3835(97)04653-3

[14] Dalluge, J.J. and Nelson, B.C. (2000) Determination of Tea Catechins. Journal of Chromatography A, 881, $411-424$. http://dx.doi.org/10.1016/S0021-9673(00)00062-5

[15] Owuor, P.O. and Obanda, M. (2001) Comparative Responses in Plain Black Tea Quality Parameters of Different Tea Clones to Fermentation Temperature and Duration. Food Chemistry, 72, 319-327. http://dx.doi.org/10.1016/S0308-8146(00)00232-6

[16] Antioxidants, E., Leung, L.K., Su, Y., Chen, R., Zhang, Z., Huang, Y. and Chen, Z. (2001) Theaflavins in Black Tea and Catechins in Green Tea Are Equally. Society, 1, 2248-2251.

[17] Łuczaj, W. and Skrzydlewska, E. (2005) Antioxidative Properties of Black Tea. Preventive Medicine, 40, 910-918. http://dx.doi.org/10.1016/j.ypmed.2004.10.014

[18] Lorenz, M., Urban, J., Engelhardt, U., Baumann, G., Stangl, K. and Stangl, V. (2009) Green and Black Tea Are Equally Potent Stimuli of No Production and Vasodilation: New Insights into Tea Ingredients Involved. Basic Research in Cardiology, 104, 100-110. http://dx.doi.org/10.1007/s00395-008-0759-3

[19] Tanaka, T. and Kouno, I. (2003) Oxidation of Tea Catechins: Chemical Structures and Reaction Mechanism. Food Science and Technology Research, 9, 128-133. http://dx.doi.org/10.3136/fstr.9.128

[20] Ngure, F.M., Wanyoko, J.K., Mahungu, S.M. and Shitandi, A.A. (2009) Catechins Depletion Patterns in Relation to Theaflavin and Thearubigins Formation. Food Chemistry, 115, 8-14. http://dx.doi.org/10.1016/j.foodchem.2008.10.006

[21] Kerio, L.C., Wachira, F.N., Wanyoko, J.K. and Rotich, M.K. (2013) Total Polyphenols, Catechin Profiles and Antioxidant Activity of Tea Products from Purple Leaf Coloured Tea Cultivars. Food Chemistry, 136, 1405-1413. http://dx.doi.org/10.1016/j.foodchem.2012.09.066

[22] Wachira, F.N., Kamunya, S., Karori, S., Chalo, R. and Maritim, T. (2013) Chapter 1-The Tea Plants: Botanical Aspects. Tea in Health and Disease Prevention, 3-17.

[23] Higdon, J.V. and Frei, B. (2003) Tea Catechins and Polyphenols: Health Effects, Metabolism, and Antioxidant Functions. Critical Reviews in Food Science and Nutrition, 43, 89-143. http://dx.doi.org/10.1080/10408690390826464

[24] Sajilata, M.G., Bajaj, P.R. and Singhal, R.S. (2008) Tea Polyphenols as Nutraceuticals. Comprehensive Reviews in 
Food Science and Food Safety, 7, 229. http://dx.doi.org/10.1111/j.1541-4337.2008.00043.x

[25] Rashid, K., Wachira, F.N., Nyariki, J.N., Wanyonyi, B., Murilla, G. and Isaac, A.O. (2014) Kenyan Purple Tea Anthocyanins Ability to Cross the Blood Brain Barrier and Reinforce Brain Antioxidant Capacity in Mice. Nutritional Neuroscience, 17, 178-185. http://dx.doi.org/10.1179/1476830513Y.0000000081

[26] Anesini, C., Ferraro, G.E. and Filip, R. (2008) Total Polyphenol Content and Antioxidant Capacity of Commercially Available Tea (Camellia sinensis) in Argentina. Journal of Agricultural and Food Chemistry, 56, 9225-9229. http://dx.doi.org/10.1021/jf8022782

[27] Yao, L.H., Jiang, Y.M., Caffin, N., D’Arcy, B., Datta, N., Liu, X., Singanusong, R. and Xu, Y. (2006) Phenolic Compounds in Tea from Australian Supermarkets. Food Chemistry, 96, 614-620. http://dx.doi.org/10.1016/j.foodchem.2005.03.009

[28] Jhoo, J.W., Lo, C.Y., Li, S., Sang, S., Ang, C.Y.W., Heinze, T.M. and Ho, C.T. (2005) Stability of Black Tea Polyphenol, Theaflavin, and Identification of Theanaphthoquinone as Its Major Radical Reaction Product. Journal of Agricultural and Food Chemistry, 53, 6146-6150. http://dx.doi.org/10.1021/jf050662d

[29] Feng, Q., Torii, Y., Uchida, K., Nakamura, Y., Hara, Y. and Osawa, T. (2002) Black Tea Polyphenols, Theaflavins, Prevent Cellular DNA Damage by Inhibiting Oxidative Stress and Suppressing Cytochrome P450 1A1 in Cell Cultures. Journal of Agricultural and Food Chemistry, 50, 213-220. http://dx.doi.org/10.1021/jf010875c

[30] Drobna, Z., Wismer, W. and Goonewardene, L. (2004) Selection of an Astringency Reference Standard for the Sensory Evaluation of Black Tea. Journal of Sensory Studies, 19, 119-132.

[31] Yanagimoto, K., Ochi, H., Lee, K.G. and Shibamoto, T. (2003) Antioxidative Activities of Volatile Extracts from Green Tea, Oolong Tea, and Black Tea. Journal of Agricultural and Food Chemistry, 51, 7396-7401. http://dx.doi.org/10.1021/jf030127i

[32] Krishnan, R. and Maru, G.B. (2004) Inhibitory Effect(s) of Polymeric Black Tea Polyphenol Fractions on the Formation of [(3)H]-B(a)P-Derived DNA Adducts. Journal of Agricultural and Food Chemistry, 52, 4261-4269. http://dx.doi.org/10.1021/jf049979o

[33] Steele, V.E., Kelloff, G.J., Balentine, D., Boone, C.W., Mehta, R., Bagheri, D., Sigman, C.C., Zhu, S. and Sharma, S. (2000) Comparative Chemopreventive Mechanisms of Green Tea, Black Tea And Selected Polyphenol Extracts Measured by in Vitro Bioassays. Carcinogenesis, 21, 63-67. http://dx.doi.org/10.1093/carcin/21.1.63

[34] Mulder, T.P., van Platerink, C.J., Wijnand Schuyl, P.J. and van Amelsvoort, J.M. (2001) Analysis of Theaflavins in Biological Fluids Using Liquid Chromatography-Electrospray Mass Spectrometry. Journal of Chromatography B, 760, 271-279. http://dx.doi.org/10.1016/S0378-4347(01)00285-7

[35] Haslam, E. (1999) Practical Polyphenolics: From Structure to Molecular Recognition and Physiological Action. Trends in Food Science \& Technology, 10, 339. 